\title{
'My job really has the best of both worlds'
}

Natalie Waylen, 30, qualified as a dentist in 2014 and is now a civilian dental practitioner within the Ministry of Defence.

$\mathrm{I}$ am regularly faced with looks of horror or disgust when I tell people I am a

dentist. These looks are often followed with the question: 'Do you just look at teeth all day?' I then confuse people even more when I tell them I am a dentist for the Army as (like myself until 12 months ago!) people don't realise that: 1) civilians can work within the Ministry of Defence (MOD) and 2) it's a really great job!

I came into dentistry in my mid-20s after first studying a degree in human physiology, working as a healthcare assistant for seven years and managing to squeeze in a bit of travelling such as climbing Kilimanjaro, spending six months in South America and going on an around-the-world trip. After returning, I started to think about a career and explored many aspects of healthcare
However, within a few weeks I was being asked to see more and more patients and was having 'training sessions' on how to try to sell private treatments. Although I enjoyed the dentistry, I really struggled with the business aspect of things and soon realised that general practice wasn't for me.

I went on to spend a year working at my local hospital as a Senior House Officer (SHO) in Oral and Maxillofacial Surgery. This was a huge change (and a huge shock) from the general dentistry I had been doing previously. My average day would consist of anything from taking teeth out, taking biopsies for oral cancer, and seeing and treating patients with fractured facial bones. I thoroughly enjoyed this placement but after a year I began to miss other aspects of dentistry such as root canal treatments,

\section{'I wanted a job where I was given the freedom to perform dentistry to a good standard without being pressured to sell private treatments or see a new patient every three minutes.'}

such as medicine, midwifery and even speech and language therapy. I eventually decided that a career in dentistry was for me.

After completing my degree at Bart's and the London I had my first experience of working in general practice. Due to an administration error, my first ever day as a real dentist involved seeing 30 patients for checkups and treatments as well as emergency cases as needed (just to put this into perspective, the most I had ever seen in a single day whilst at university was five patients!).

To my surprise I really enjoyed working under pressure and learnt a lot very quickly. placing restorations and even the odd scale and polish.

I set out to look for a job where I could get back into general dentistry and also have the support to continue to develop my oral surgery skills. I wanted a job where I was given the freedom to perform dentistry to a good standard without being pressured to sell private treatments or see a new patient every three minutes. Little did I know that this would be as a civilian dentist in the military.

My job really has the best of both worlds. I am able to perform the general dentistry that I missed and this time I have control over my

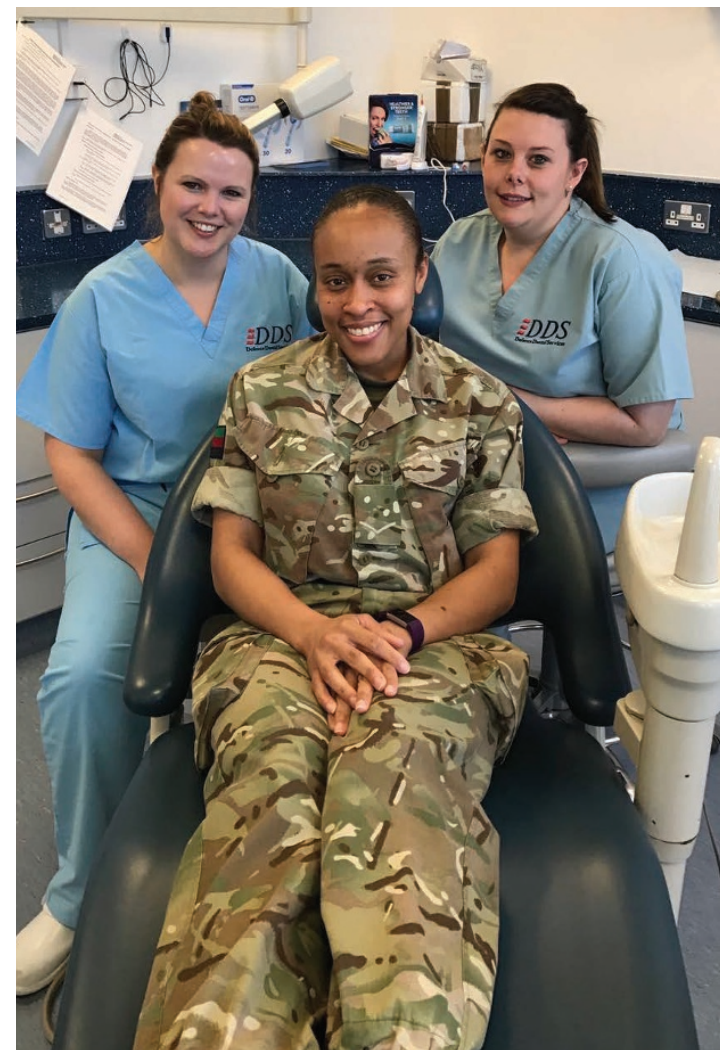

diary so I can take as long I need to ensure that I can work to the best of my ability. I also have the freedom to perform whatever treatment is best for that patient with no awkward money conversations. The organisation's priority is to ensure that all patients are dentally fit, allowing them to travel and work as part of a planned trip or as a short notice deployment without dental problems.

Along with the lack of time constraints there are many other perks to the job. CPD, which is often a bugbear of healthcare professionals, is provided free of charge at monthly regional training days. GDC registration is paid for, and the MOD is very keen to support all staff - both military and civilian - in career progression such as postgraduate training and professional exams. It is even possible to do fully-funded higher postgraduate training such as an MSc through the job.

Along with the professional aspects I have also benefitted personally from the job - I have met some people whom I never would have crossed paths with otherwise. Each day is varied, and I am always exchanging stories with both patients and colleagues about the exotic places they have travelled and the experiences they have enjoyed. 